\title{
Dry Shipper
}

National Cancer Institute

\section{Source}

National Cancer Institute. Dry Shipper. NCI Thesaurus. Code C95531.

A container used to ship products frozen in liquid nitrogen. It is designed so that the liquid nitrogen is absorbed into retention medium that surrounds the samples and maintains them at liquid nitrogen temperatures. 